\title{
Efficiency of the construction market and need for government regulation
}

\author{
Aneta Marichova
}

Abstract -For a long time in economic theory and practice, regulation is only linked to the need for state intervention in monopolistic markets, by developing uniform, simple regulatory rules to limit and control the monopoly power, the monopoly price, mergers and acquisitions between companies in the same industry and others. In recent years the prevailing opinion that government regulation is particularly necessary in oligopolistic markets where there are several leading, dominant companies that can influence the price, quantity and quality of the product offered. However, this regulatory policy should not apply to common rules and taking into account the specifics of the market/industry, market structure (concentration level) of the various market segments and the relevant economic activity. The aim of the study: 1) Evaluation of the efficiency of the construction market, 2) Demonstrate the need for government intervention, 3) Guidelines for the implementation of the regulatory function of the government.

Keywords -construction firm, construction market, efficiency of the construction market, government intervention and regulation

\section{INTRODUCTION}

Traditionally, market efficiency is assessed on the basis of realized production efficiency, companies produce with minimal average cost $(\mathrm{P}=\mathrm{ACmin})$, allocative efficiency, meaning that products are produced at an optimal combination of resources, the price is equal to the marginal cost $(\mathrm{P}=\mathrm{MC})$ and social efficiency that provides social justice (employment, fair distribution of income, additional value for consumers and society as a whole, etc.). In the imperfect markets (oligopoly and monopoly) with a high degree of concentration, there are few firms that create a

Manuscript received $1^{\text {th }}$ August 2017

Aneta Marichova - the University of Architecture, Civil Engineering and Geodesy, 1, Hristo Smirnensky Boulevard, 1046-Sofia, Bulgaria (corresponding author e-mail:aneta.marichova@abv.bg, marichova_fte @uacg.bg) 
standardized or differentiated product, there are high barriers to entry, the price is higher than the marginal cost and the minimum average costs, there allocative and production inefficiencies. The proven inefficiency in the operation of highconcentration markets requires government intervention. It can be implemented in the following ways: restricting market monopolization, merger control and corporate takeovers, cartel agreements, coordination of prices, price discrimination, legal regulation of the activity, the system of taxes, subsidies, as well as through the overall macroeconomic policy.

For a long time, government intervention has been associated only with the need to regulate the monopoly and especially the natural monopoly, but in recent years the prevailing opinion [1] that government regulation is particularly necessary in oligopolistic markets, where there are several leading, dominant companies that can influence the price, quantity and quality of the product. This regulatory policy should not apply to common rules and taking into account the specifics of the market/industry, market structure (concentration level) of the various market segments and the relevant economic activity. The aim of the study:1) Evaluation of the efficiency of the construction market, 2) Demonstrate the need for government intervention, 3) Guidelines for the implementation of the regulatory function of the government.

\section{EVALUTION OF THE EFFICIENCY OF THE CONSTRUCTION MARKET AND NEED FOR GOVERNMENT INTERVENTION - THEORETICAL FOUNDATIONS}

Regardless of the general characteristic on the construction market that this is a market on which work too many, small firms with limited resources and capacity creating a similar product, the misconception is that the market structure can be defined as perfect competition. In-depth market research proves that there is a high heterogeneity, and therefore it is difficult to classify all companies into a marketbased model. The construction market includes different market segments, as from the viewpoint on the different buyers and their different behaviors, as from the viewpoint on the companies offering these services (different construction activities with different geographic, territorial locations). One of the most significant features of construction production is its immobility, an immediate link to the land where it is built and subsequently consumed combined with mobility of companies and resources. The specificity of the industry as tied primarily territorial within a particular region or the country as a wholerequires evaluation of its effectiveness to be done within both the national level and in individual regions of the country.

The study of the market structure based on three objective indicators (number and size of sellers and buyers, product differentiation, entry barriers) and two market measures (concentration ratio and the Herfindal index) shows that at national level the competition of on the market of building (residential and non-residential) construction is efficient, monopolistic, and on the market of civil engineering is an oligopoly with a homogeneous or differentiated product. In all regions, however, there is a high 
degree of concentration on the construction market. The dominant market structures are an oligopoly or an oligopoly with a leader (the company leader has a market share of 50-60\%) or a duopoly, with the two leading companies sharing the market almost proportionally in each region, or there is only one, monopoly firm that controls over $80 \%$. By definition, this is a condition for a formal or informal agreement between the companies for the separation and control of the market, which leads to market defects. These companies usually work on the market of civil engineering and the market of non-residential construction and their activity is always relating to public contracts for repair of roads, public buildings which creates the impression of unfair competition unregulated relationships with the procuring institutions.

Construction firms working on the market of civil engineering are few in number, with strong specialization and asset differentiation, each with a significant market share. By definition, this is a condition that allows them to increase or stabilize their market positions even in a sharp drop in the industry. They create similar products which are close substitutes and have very similar average costs, which excludes price competition. The market structure under these conditions is defined as an oligopoly with one or two dominant companies. This means strong interdependence and dependence on firms, which requires some coordination of company policies (cartel) and some agreement to achieve the common goals.

The other weaker firms take the dominant position of the leading companies and do not react to politics, the leader's actions as silently follow him in his pricing, product and advertising policy. Very often a dominant company in a given market is the company with the lowest cost, which means an objective opportunity to determine and maintain relatively lower prices and to realize higher profits. This limits the access of new companies in this market, and for smaller operating companies, maintaining price leadership is often a matter of survival.

In an oligopolistic market, such as construction, the company's behavior implies both the absence and presence of collusion (cartel) with the other competitors, but in any case means interdependence andinvolvement of companies in a given market. Dominant strategy for big companies is a conscious policy of agreements and agreements between companies based on a secret agreement or a "follow the leader" policy, which aims to stabilize and increase their market positions, at the expense of competitors' positions and as a result limiting entry of new competitors. Agreements are secret, varying degrees of gradation, informal, tacit consent, and ultimately corporate behavior that manipulates and changes the market in order to divide, control, and increase profits. Firms' participation in these agreements provides higher profits and a higher market share. Because of the low entry barriers and market dynamics, these agreements are usually short-lived, but provide more full capacity utilization and higher profit by maintaining a higher price [2]. It is well known that in all countries such agreements are illegal and therefore it is very difficult to establish and prove them,but in all countries there are enough examples of, agreements (secret or implicit) and restrictive practices of companies. They can be realized in different ways: the offers submitted by the companies are absolutely identical or unusually different or extremely inaccurate to the announced requirements of the auction, or suspectly high offers are made, without objective justification for cost increases [3]. 
Win a company that has secretly negotiated with others to maintain such unreasonably high prices. Eventually, the organizers of the auction are those who pay the high price, and the participants play as a cartel with clearly defined decisions who at what price will win the contract. Such agreements often include payment terms for companies that refuse to support the high price, but pay is more often related to future benefits, future bidding, future contracts, and more.

At the same time, the practice provides enough examples of restrictive actions not only on the part of oligopolistic firms but also for restrictive actions on the part of investors and contracting entities (state, public and local institutions) which blocks the entrance, limits the number of competing firms and strengthens the monopoly positions of one or two companies that always win auctions in individual regions. This non - legitimate policy is implemented by imposing excessive and unnecessary requirements from the assignor which eliminates over a third of the bidders in the construction auctions and allows the "right" firm to be chosen.

The shrinking construction market exacerbates competition between companies, and mainly through illegal practices through which they can expand their position on the market. Companies are trying to restrict competition because the imperfect market provides them with higher profits, but the oligopoly creates uncertainty, so they resort to agreements to maximize their profits. The government should strive to stimulate competition and effective resource allocation. Its purpose is to restrict conduct that is against the public interest.

In many regions of the country, the municipality as contracting procurement (mainly for maintenance and repair of roads) works with one or up to two companies, which each year win the auction or renew their contract. On one side is a proof of high specialization of these companies In the activity performed, for stability in the relationship between the buyer and the seller, but also for the high market power of the monopolistic companies, a function of the high concentration of the construction market in the given region. The doubts about opacity can not be ruled out when conducting local auctions, preliminary arrangements for who will win the auction and artificially raise prices on the basis of collusion between the bidders. In the public procurement system not infrequently, the company won the tender with the lowest price use their dominant position in relation to the assignor and starts updating the contract to increase the price, which highlights a number of unexpected, eventually arising problems that require additional activities and cost the site or extend its duration. These realities on the market of civil engineering require a change of rules to stop the vicious practice the orders are always to be won by the same companies, and profit is shared between the winning companies and the contracting authorities. The market power of construction firms in individual regions isjust result of these agreements and illegal practices which are a function of the ineffectiveness of the current legislation.

The analysis of the behavior of the two players (buyer and seller) on the market of civil engineering talks about existing imperfections (market defects) and inefficiencies that require government intervention and regulation. Market failures and reduced efficiency on the market of civil engineering are the result of the constraints created on the one hand investors who announce public tenders, which are 
even more difficult to carry out even by large, serious construction companies (especially in a crisis of this market) and on the other hand, the actions of several large operating companies that participate in the market with secret or quasi (implicit) agreements, which restricts competition and the entry of new competitors. Thus creating unnatural, ineffective competitive advantages of certain selected companies.

The public sector is a major player in this market and its main task is precisely to provide an optimal mix of input resources and efficient use of technology to reduce losses and increase the benefits to society. This makes state intervention particularly necessary and its main task is to address unethical corporate behavior in the interest of the whole society limiting restrictive agreements which restrict competition and reinforce price controls.

The main direction of government intervention in imperfect markets is the control of horizontal and vertical mergers that lead to monopolization of the market. The main reason for these processes are the possibilities for increasing the market power, realizing a higher return on the total assets of the newly established company, the opportunity to enter a new market or easier entry into a foreign market, expanding the product range through diversification of the activity, reducing the risk of specialization of the company, increasing credit confidence for the new firm and others. The ultimate effect is to realize traditional economies of scale or economies of scope that increase the company's technological competencies and create opportunities for using and transferring larger cash flows, stimulating research and innovation, expanding and stabilizing market positions and competitive advantages of operating firms, but these associations can also block entry into the market and reducing its effectiveness in the future [4].

Typically, leading construction companies have complex holding structures that bring together a large number of subsidiaries specialized in a particular activity from the different stages of the construction process or in the production of a product for a particular market segment. This is evidence of the high degree of horizontal integration achieved in them, which is an important condition for their higher efficiency - realized economies of scale, pooling more financial resources and flexibility, adaptability to market changes. In addition, these companies include in their structure and companies related to investment activity, the valuation and realization of real estate and of course the production and trade of building materials. Therefore, in addition to horizontal mergers, there are also vertical ones that cover the whole vertical relationship process, eliminating the power of suppliers and buyers. The policy on mergers and acquisitions intensify especially in a sharp drop in construction activity there are also volunteer acquisitions of smaller firms with difficulty in operating from the larger ones.

The specific nature of construction as an economic activity and ofconstruction products (goods and services) determine the existence of a complex vertical chain of relations and relationships involving different subjects as buyers and sellers and performing different functions in the entire construction process (fig. 1).Research area includes hydrotechnical constructions of the undercrossing Timişeşti-Iași adduction pipes of Moldova River. In the undercrossing zone are three adduction pipes: the first 
adduction pipe (Ad I), put into operation 1911; two adduction pipes (Ad II), put into operation in 1973.

On river Moldova is performed a hydrotechnical construction of undercrossing transmission pipes. Settlers in the area of research consist of layers of ballast with thickness of $18 \ldots 15 \mathrm{~m} \mathrm{[5].} \mathrm{The} \mathrm{section} \mathrm{of} \mathrm{river} \mathrm{regulation} \mathrm{work} \mathrm{has} \mathrm{a} \mathrm{bed} \mathrm{and} \mathrm{shore}$ protection. Shore protection works were carried out in the 1970...1973. Defending the shore is formed by massive stone upon which were placed concrete pears. Moldova River over a length of $325 \mathrm{~m}$ presents the current stage a channel linear calibrated. The river bed was calibrated to determine high flow speeds of floods.

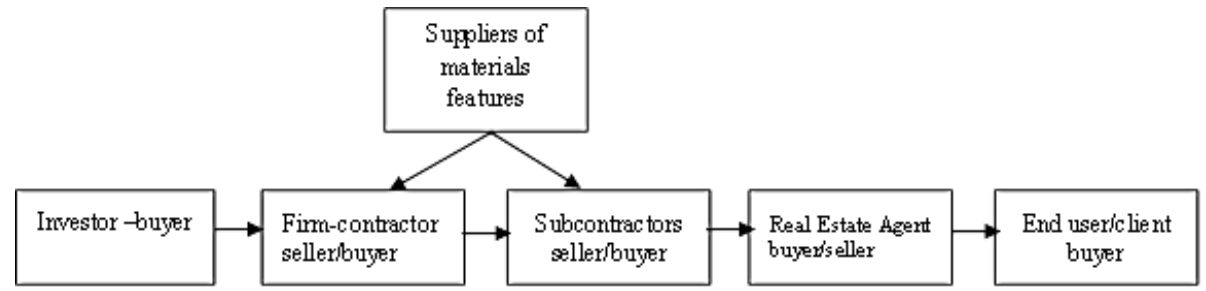

Fig.1. A vertical chain of relationships between different entities (buyers and sellers) involved in the construction process

In this vertical chain, a major factor, which influences the construction is the investor -contracting authority and buyer of the given building site by the construction firm-contractor (seller) on the site. In turn, it works with subcontractors, which entrusts the execution of certain tasks and functions to the realization of the final product. The executive firm is now the buyer, subcontractors - sellers of the service. The realization of the finished product means that the investor and the construction company are the sellers of this product to the end user. Consequently, the participants in the construction process perform consistently both the function of a buyer and a seller of the product. Any unit in this chain may occur, forming a monopson or oligopson of the buyer, or a monopoly or oligopoly of the seller. In principle, the monopoly position of a company participating in this chain may create conditions for the realization of a monopoly high profit, and another firm in the next unit, which is a factor in reducing the efficiency of the construction market.

The market of civil engineering is a typical market for a monopson buyer of a specialized production, and that is usually the government and the municipalities, and the seller on this market is a monopoly (or oligopoly, duopoly), ie a large company with differentiated assets and specialized in the construction of large objects. Apart from the government, a monopson buyer of a particular specific construction product can be also big companies with specialized production, which usually work with one, also narrowly specialized construction company in the construction of the desired objects and the implementation of the necessary maintenance. Practice examples show the extremely tight and lasting ties that build between the buyer and the seller on such a specialized market, which guarantees the security and stability of both countries' activities. In such a market, obviously the objectives of the two players with market power and the factor and the product market can hardly be realized at the same 
time and it is difficult to give a clear answer as to how their interests will be met. It is certainly possible to determine the price limits within which the negotiations will be conducted. Achieving a deal is far from simple, especially when the participants exert strong pressure and try to put each other in the corner. The buyer's power must be sufficient to keep monopoly increases in producer prices, but not too large to prevent the buyer from setting monopoly prices when he or she will act as the seller of his own production. Awareness of this unfavorable opportunity as a result of the bilateral monopoly, has led the seller and the buyer to strive for a relatively stable relationship, which is often achieved through vertical integration of successfully functioning units of the production process into a single chain but which creates barriers for other firms. Therefore, an important aspect of government regulation in oligopolistic markets is the regulation of vertical relations and relationships between firms involved in the vertical chain of value creation.

\section{GUIDELINES FOR GOVERNMENT REGULATION ON THE OLIGOPOLISTIC MARKET OF CIVIL ENGINEERING}

The evaluation of the efficiency of the construction market and the existing defects resulting from restrictive actions of the companies and of the public procurers, the complex relations in the vertical chain, etc. determine the main guidelines for government intervention and regulation on the oligopolistic market of civil engineering taking into account its specificities (Fig.2).

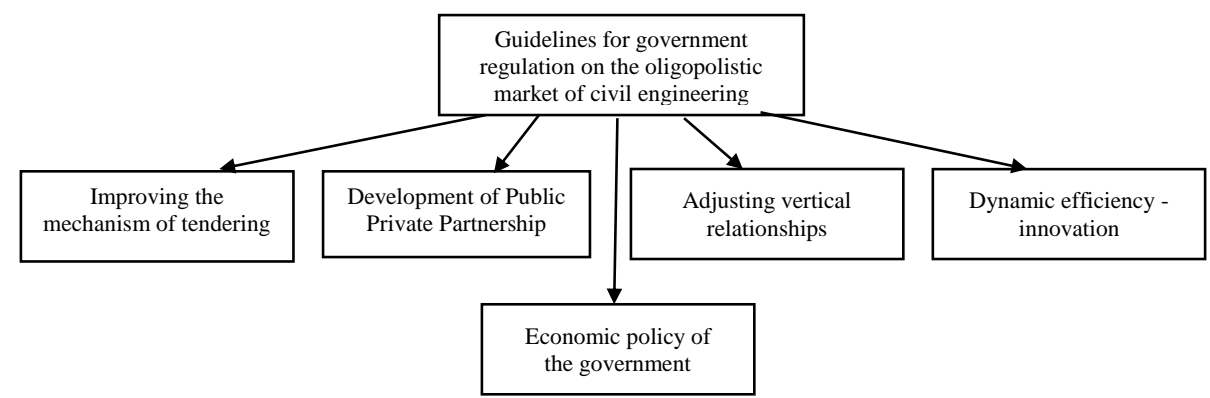

Fig. 2 Guidelines for government intervention and regulation on the oligopolistic market of civil engineering

\subsection{Improving the mechanism of tendering}

Improving the tender mechanism requires government regulation on the oligopolistic market of civil engineering in the following directions:

1) Reduce asymmetry of information. The regulator never has full and accurate information about the costs, the technology used, the performance of the companies operating on the market and potential bidders. Reducing asymmetry in information can be achieved by developing not a single offer and contract respectively, but the development of a kit (set, menu) from different offers/contracts with different 
parameters (price, performance, quality, guarantees, etc.). Each company participant in the tender offer will select and contract according to their expectations and their capabilities. Effective firms with the ability to reduce, optimize the cost of the site (and consequently make a higher profit) will choose to offer a lower price and vice versa. Developing and offering just one offer (often at an increased or low price but with the possibility of constant updates due to unforeseen situations) allows the winning bid to make a high profit, provided it has the potential to optimize and reduce costs, which increases market failures.

2) The second important problem is related to determining the period for which it is conclude contracts between the contracting authority (the public sector) and the firm. Practice shows that usually concluded contracts are short-term but repetitive over time and always with the same firm (which explains the high level of concentration and market power of one or two companies per region in the country). Assuming that a company has the potential to reduce costs and make a high profit from a short-term contract the probability that this information reaches the assignor and other controllers is large and, respectively, on a subsequent order to bet a lower price, which would deprive the company of the opportunity to make a high profit. For these reasons, naturally, short-term bargaining has no interest in reducing costs and increasing efficiency. In such a case, the development of a set of long-term contracts can be a powerful factor for companies to work rationally and to reveal their advantages in the business, which can, of course, also improve the overall picture of the industry.

3) In organizing and conducting tender procedures participate different actors (government, public, regional, local institutions, firms) that are hierarchically linked and dependent. The desire to win the auction and the various intertwined interests open up opportunities for collusion, agreements, coordination of rules of the game, concealment of information, opacity, bribes at all levels, and the end result is a distortion of the auction and a reduction in market efficiency. In this regard, the government has one main task - to develop an effective framework for organizing and conducting each auction to limit and reduce this opportunity.

Problems and doubts of dumping and illegal practices in auctioning of large civil engineering (infrastructure) projects requires a change of rules by the investor government. The new rules on tendering procedures include the idea orders to be advertised as engineering (design and construction). But the important difference is in a different direction - a complete change in the model that candidates will be assessed. The "lowest price" criterion remains in the past. The basis of choice is a combination of price, method (technology) and period of performance. The three components will have a different weight in the final grade. One of the possible options is the price to have a $60 \%$ weight, and the other criteria - $40 \%$. In applying this new method of organizing and conducting large procurement tenders, the evaluation involves two phases:

The first phase will be a preliminary classification according to certain criteria technical and financial, as companies will prove that they are financially stable, have history, qualified staff, machines. According to her experience, access to finance will be made short list of construction companies or unions that will go ahead. In parallel, 
will run the preparation of conceptual design for the site.With its completion, the second phase of the tender procedure will begin. In it, each of the candidates who have passed the first phase will prepare a detailed implementation project, which will be evaluated by price, technical parameters and term, ie. On the principle of "Most economically advantageous tender".

Putting construction companies in new competitive conditions is an important factor not only for their own economic development but also for increasing the overall efficiency of the market.

\subsection{Development of Public Private Partnership (PPP)}

The regulatory function of the government to increase the efficiency on the oligopolistic market of civil engineering is also related to the development of the Public Private Partnership (PPP). Practice shows that problems related to the public procurement system which is substantially flawed and compromised can be largely resolved through the PPP system.

PPP is a long-term contractual relationship between private and public sector clients to finance, build, reconstruct, manage and maintain the infrastructure to achieve a higher level of service, with the private partner taking the risk of construction and at least one of the two risks associated with the availability of the service or its search. Payments for the service provided by the private partner are tied to its quantity and quality, and the government reduces its payments when providing a service other than the desired quality and quantity. Until now, the government has traditionally financed the construction of infrastructure by paying for the realization of the site of a contractor. After completing the construction activities, it undertakes the maintenance and operation of the sites, taking all the risks associated with their construction and operation - increased prices over the forecasts, quality control, execution in time, etc. The PPP system provides financing, investment in public infrastructure, and requires a reorientation of the government from a policy of acquiring assets to a policy of receiving a service when the government budget and municipal budgets do not have the necessary resources.

The creation of PPPs requires the active involvement of banks, consultancy firms to help determine the structure, relationships of the actors involved and to share the risk. The benefits of PPPs, as shown by the world practice, are associated firstly with the lower price, higher quality and timeliness of the implementation of the sites implemented by the private partners, with which theyIncrease the efficiency of their work and minimize risk. PPP combines the innovation, experience and business sense of the private sector with the ever-growing need of the public sector for good infrastructure, which also ensures greater efficiency for taxpayers.

\subsection{Adjusting vertical relationships in the construction market}

The construction company must develop and build its relationships with other companies (buyers and sellers) from the vertical supply chain, based on competitive conditions created and maintained by the government. A major mechanism should be the application of antitrust lawsWith regard to the control of vertical mergers, takeovers, vertical integration processes which restrict competition, create conditions 
for the imposition of monopoly prices, the realization of monopoly profits and the generally deform the market. The most effective form of competition can be realized in the system of an integrated supply chain that operates on the basis of permanent relationships and exchange of information between the involved entities -investor, a construction company-contractor, subcontractors, end customers and so on. The basis for effective joint work in the integrated supply chain is trust. Effective connections between all participants coupled with effective supply chain management of building materials with other good practices of customer relationship management ensures greater competitiveness and efficiency in the market and the construction firm.

\subsection{Dynamic efficiency - competition and innovation in the construction market}

Under the contemporary conditions the efficiency of a market is determined primarily by its dynamics and the realization of dynamic efficiency. Each market is defined as dynamic or static depending on the barriers that exist for entry and/or exit and the number of companies entering and/or leaving (i.e. birth rate and market mortality).Static market has high barriers to entry of new firms. The existing companies create and sell similar products by competing primarily through the price, and the economies of scale are a major source of competitive advantage. In dynamic markets, innovation and competitive advantage through differentiation and the creation of a new product and/or process that reduces the market share and market power of other companies is a key factor for competition and efficiency. This shows that they have just reached $\mathrm{X}$-inefficiency because they use less knowledge, less research and performance improvements than new entrants who logically have a better chance of survival. On the dynamic market there is constantly a threat from new businesses to enter or some of the smaller companies in place to develop and occupy more stable market positions through innovation and higher efficiency. Under these conditions, existing firms are hardly able to block the input and the scale of production achieved and the cost advantages realized are of little importance. The success and/or survival of each firm (and current and new) in dynamic, even highconcentration markets is a function of the development of knowledge, innovation and offering novelties, which adds value to the consumer and is a key factor in building a competitive advantage [5].

One main guideline in which restricting competition on the construction market can have a positive effect on society is linked to state support for the creation of unions - "pools" between major, leading, oligopolistic companies to unite financial, material, human resources to enable the development of innovation and realization Of strategic investments with minimal risk. This is a major factor for the realization of dynamic efficiency of the construction market.

\subsection{Impact of the economic policy of the government on the construction market}

Construction is an important branch of any national economy because it affects many aspects such as production, employment, income, sustainable development. In a crisis, the significant position of this sector is proven through the place it occupies in short, medium and long-term government programs. The stimulation of construction 
can be achieved by creating better conditions for the construction companies to work and attracting and increasing foreign and national investments.To this end, economic actions and policies are needed, Which will have a positive impact on this market, and will have direct and indirect effects on the overall development of the economy, but they depend on the capabilities of each country. Practice shows that we can talk about two stages in which government intervention influences construction:

1) Short-term government measures - fiscal and monetary - to stimulate demand by increasing public investment. In many cases, they reduce the impact of cyclical fluctuations on the construction market by stimulating private and investment demand, ensuring the survival of a large number of small firms, such as contractors and subcontractors of government procurement, and allowing the private sector to return quickly to market as a major player.

2) At the next stage, the government restricts its direct participation and provides conditions for stimulating the business through long-term measures, which are an incentive for changes in supply. These are mainly activities related to public investment in research and education, enhancing the environmental friendliness of the economy, supporting innovation in small and medium-sized enterprises, protecting intellectual property, incentives and support for its complementary and interconnected activities in the vertical supply chain.creating effective links between companies and the public sector. These actions lead to the development of the internal intangible assets of the firm and have as a result a change in the supply of the construction market.

Therefore, the economic policy of the government to stimulate and ensure stable long-term growth on the construction market must be simultaneously in line with the rising demand and consumption, resulting from higher employment, income, and the creation of favorable conditions for innovation and investments, i.e. change in supply.

Increasing the efficiency of the construction market puts as a primary task of the government the creation of standards and requirements for sustainable development. Its role in this direction is to create mechanisms, renewal models, guarantee funds, regulatory frameworks, fiscal incentives for investors and users of sustainable construction products. The new conditions require strategic and flexible cooperation between the private sector and the government. External conditions have a strong influence on the internal conditions and opportunities for company development. The government and local authorities must ensure better market conditions and necessary resources not only in quantity but mainly in quality and the necessary capacity for development and change of firms that goes beyond securing property rights, contract performance, and the basic functions of modern management.

It is necessary to develop a new model in which the state as an economic entity creates conditions for cooperation between different companies with educational and research institutes and development of new opportunities for business promotion, inter-company cooperation and support for the building and development of new competencies in the company. The logical result is a combination of efforts, potential, resources of the private and public sectors for working together and recognizing the priority of education and research or, in short, the creation of clusters that are a strong factor in achieving sustainable economic growth. 


\section{CONCLUSIONS}

The subject of research in the paper is one current problem - the efficiency of the construction market and the need for state intervention, taking into account its specificity. The construction market is a non-homogeneous market, primarily linked to a region or country as a whole, and involving different market segments, with different players (like buyers and sellers) with different market positions and different market power.

Research on the on the market of civil engineering both at national level and in individual regions of the country proves strong positions of a monopoly company or two companies (duopoly) or an oligopoly with a homogeneous or differentiated product that is a condition for a formal or informal agreement (cartel) between them or with the contracting authorities (purchaser-monopson) and therefore for market partitioning and control.

From a theoretical point of view this is a sufficient condition for the existence of market defects, which objectively implies government intervention and regulation of the market. The author proves that the guidelines in which a government's regulatory function is to be implemented are related primarily to the improvement of tendering procedures by reducing the asymmetry of the information at its disposal, concluding long-term (rather than short-term) contracts that create incentives for companies to improve their business and work more efficiently, creating an effective framework for organizing auctions, which does not allow for game rules, concealment of information, opacity, bribes at all levels, and the end result is a distortion of the auction and a reduction in market efficiency. Needed is a complete change of model, the criterion "lowest price" of the past and the choice of contractor is already on a combination of price, method and period of performance.

The role of the government and the public procurement system as a factor for the development of the construction market will become increasingly limited and the efforts should be directed to an accelerated development of PPPs. One main guideline in which the restriction of competition may exist a positive effect for society is related to the creation of pooling - pooling between big, leading, dominating, oligopolistic companies on the market in order to unite financial, material, human resources to allow the development of innovation and the realization of strategic investments with minimal risk. This is a major factor for the realization of dynamic efficiency of the construction market. It is necessary to combine cleverly the short-term government measures which stimulate demand with long-term government measures aimed at changing supply. They are a function of additional government investment in research and education, the establishment of government standards and requirements for sustainable construction, which is an important factor for the development of innovation at a radical level of industry, support for innovation in small and mediumsized enterprises, protection of intellectual property, creating effective links between companies and the public sector, stimulating and supporting complementary and interconnected activities in the vertical supply chain, etc. The aim of all these government actions is to increase the efficiency of the functioning of the construction 
Ovidius University Annals Series: Civil Engineering, Issue19, $2017 \quad 49$

market, a factor for creating additional benefits for the clients and society as a whole, and combining the interests of society, investors (clients) and construction firms.

\section{REFERENCES}

[1]. Bridge A., C.Tisdell, (2006), The Determinants of the Vertical Boundaries of the Construction Firms, Construction Management and Economics, (22 /8), pp.807-825

[2] Gruneberg S., Ive G., (2000), The economics of the modern construction firm. Macmillan Press Ltd.

[3] Myers D., (2008), Construction Economics: A new approach. Second Edition. Taylor \& Francis. London \&New York, pp.132-135

[4] Tirole J. (2014), Market Power and Regulation. Royal Swedish Academy of the Sciences. http:// www.nobelprize.org.

[5] De Valence G., (2003), Market Structure, Barriers to Entry and Competition in Construction Markets, Dept. of Building, National University of Singapore, pp. 819827 